Original Article

\title{
HIBISCUS ROSA SINENSIS LOADED SOLID LIPID NANOPARTICLES AND IN VIVO WOUND HEALING ACTIVITY IN WISTAR ALBINO RATS
}

\author{
VIJAYANAND P. ${ }^{*}$, JYOTHI V. ${ }^{2}$, MOUNIKA A. ${ }^{2}$ \\ 1Department of Pharmaceutics, Rani Chennamma College of Pharmacy, Vaibhav Nagar, Belagavi 590019, Karnataka, India, ${ }^{2}$ Sri \\ Venkateshwara College of Pharmacy, Madhapur, Hyderabad 500081, Telangana, India \\ Email: vijay.svcp@gmail.com
}

Received: 23 Jan 2020, Revised and Accepted: 15 Mar 2020

\begin{abstract}
Objective: The objective of the present research was to investigate the wound-healing potency of solid lipid nano particles of Hibiscus rosa sinensis extract. Crude herbal extracts and rudimentary formulations containing herbal extracts are good for demonstrating the feasibility of the concept; however, such formulations suffer with poor oral bioavailability and variability within groups of subjects. Converting herbal extracts into novel drug delivery systems may prove effective in addressing some of these problems.
\end{abstract}

Methods: In the present study an attempt was made to develop Hibiscus rosa sinensis extract loaded solid lipid nanoparticles (HSLNs) using lipids glycerol monostearate (GMS) or beeswax. The prepared HSLNs were characterised for their size, surface charge and morphology. The optimized HSLNs were incorporated into Carbopol gel and tested for wound healing activity in male Wistar albino rats using excision wound model.

Results: HSLNs of $\sim 175 \mathrm{~nm}$ in size carrying negative charge were obtained with the optimised procedure using beeswax. The shape of the HSLNs was nearly spherical. The HSLNs $(10 \mathrm{mg} / \mathrm{ml})$ treated wounds healed much faster compared to raw crude extract and healing was comparable to marketed preparation.

Conclusion: It is concluded that converting crude herbal extracts into SLNs can be an effective way to enhance the effectiveness of herbal extracts and their in vivo activity.

Keywords: Solid Lipid Nanoparticles, Hibiscus rosa sinensis, Wound healing, Glyceryl monostearate, Beeswax

(C) 2020 The Authors. Published by Innovare Academic Sciences Pvt Ltd. This is an open access article under the CC BY license (http://creativecommons.org/licenses/by/4.0/ DOI: http://dx.doi.org/10.22159/ijcpr.2020v12i3.38311. Journal homepage: https://innovareacademics.in/journals/index.php/ijcpr

\section{INTRODUCTION}

Effective wound care and management relies on mainly on the development of novel and effective formulations. Chronic wound care management will continue to be a focused area of research [1]. The process of wound healing involves a series of events leading to the repair wound of injured tissues [2]. Three phases associated with wound healing are: inflammatory phase, proliferative phase and remodelling phases. The rate of reepithelialisation and angiogenesis determines the healing of wound lesion [2]. The process of wound healing may also be delayed by aerobic and anaerobic bacterial infections. The bacteria involved are Staphylococcus aureus, Streptococcus and Enterococcus species, Coliforms, Pseudomonas aeruginosa, and Peptostreptococcus [3, 4].

Recently, much attention have been given to solid lipid nanoparticles (SLNs) by the scientists working in the nanotechnology because of their unique properties [5]. SLNs are submicron size carriers ranging from $50-1000 \mathrm{~nm}$ and are made up of lipids that are biocompatible and biodegradable [6,7]. These lipids are capable of incorporating both lipophilic and hydrophilic drugs [8]. SLNs have been perceived as excellent carriers for the delivery of several drugs like antidepressants, anticancer agents [5], antioxidants and wound healing $[9,10]$. It was reported that using nanotechnology could shorten the process of wound healing, reduce the treatment costs and enhance patient compliance [10]. SLNs are particularly useful in enhancing the bioavailability of drugs that are used in treating CNS disorders [11]. SLNs of silver sulfadiazine have been tried in wound dressings for tissue repair [12].

Hibiscus rosa sinensis Linn. (Malvaceae), China rose, is an ever booming and ornamental plant.[13] It is mainly found in tropical and subtropical regions and reported to posses various potential medicinal properties including antitumor, antihypertensive and antioxidant $[14,15]$. The leaves and flowers of this plant has been shown to promote hair growth and ulcer healing properties $[16,17]$. Flower extract was found to be effective in arterial hypertension [18] and depression [19]. Animals treated with hibiscus rosa sinensis exhibited significant $(86 \%)$ reduction in wound area compared to controls [20]. Ethanolic extract of flowers of rosa sinensis was found to have greater wound healing property than the nitrofurazone ointment [21].

We have previously reported the antidepressant activity of the HSLNs[19]. In this study, we hypothesized that these HSLNSs owing to their size and composition may enhance the wound healing property of the extract. Hence this study was undertaken to investigate the effect of SLNs of hibiscus rosa sinensis on wound healing.

\section{MATERIALS AND METHODS}

\section{Material}

Hibiscus methanol extract was purchased from Kshipra Biotech, Indore, India, Glyceryl monostearate (GMS) was procured from Adithi foods and Paper products (Hyderabad, India), Tween 80 and Soybean lecithin were procured from Lipoid $\mathrm{GmbH}$ (Ludwigshafen, Germany). Beeswax was purchased from Sigma Aldrich, Mumbai, India. All other chemicals used were of laboratory grade.

Preparation of solid lipid nanoparticles of Hibiscuss rosa sinensis

We have previously reported the method of preparation of HSLNs using GMS and beeswax [19, 22]. The prepared free flowing HSLN formulations were stored at room temperature in air-tight glass containers until further use. Typical formulation compositions are shown in table 1. 
Table 1: Formulation composition of GMS HSLNs

\begin{tabular}{lll}
\hline Formulation & Ingredients & Amount (\% w/w) \\
\hline F1 & Glyceryl monostearate & 3.5 \\
F2 & Beeswax & 7.25 \\
& Hibiscus rosa sinensis Extract & 0.1 \\
& Soy lecithin & 0.6 \\
& Tween 80 & 2 \\
Milli Q Water & q. s. to 100 \\
\hline
\end{tabular}

\section{Preparation of carbopol gels}

Carbopol-940 was dispersed in $50 \mathrm{ml}$ of distilled water. It was kept aside for $30 \mathrm{~min}$ for complete hydration and stirred to form gel [23, 24]. Specified quantity of methyl and propyl paraben were separately dissolved in $5 \mathrm{ml}$ distilled water with the aid of heat on water bath. Solution was cooled; PEG-400 was added to it with stirring. Equivalent amount of freeze dried HSLNs were added to get
$2 \mathrm{mg} / \mathrm{ml}, 5 \mathrm{mg} / \mathrm{ml}$ and $10 \mathrm{mg} / \mathrm{ml}$ to the above mixture and volume was made up to $50 \mathrm{ml}$ with distilled water. All remaining ingredients were added with continuous stirring. Triethanolamine used to adjust the $\mathrm{pH}$ between 6.8 and 7.0 and to obtain a required consistency of the final gel. The composition of gels is shown in table 2. Prepared gel formulations were carefully filled in collapsible tubes and stored at room temperature until further evaluation $[25,26]$. Crude extract of hibiscus (10 $\mathrm{mg} / \mathrm{ml}$ ) was incorporated in the $\mathrm{F} 1$ formulation.

Table 2: Formulation of carbopol 940 gel

\begin{tabular}{|c|c|c|c|c|}
\hline \multirow[t]{2}{*}{ Ingredients (\%w/v) } & \multicolumn{4}{|c|}{ Formulation code } \\
\hline & F1 & F2 & F3 & F4 \\
\hline HSLNS & 0 & 100 & 250 & 500 \\
\hline Crude extract & 500 & 0 & 0 & 0 \\
\hline Carbopol-940 & 1.5 & 1.5 & 1.5 & 1.5 \\
\hline *PEG 400 & 5 & 5 & 5 & 5 \\
\hline Methyl paraben & 0.2 & 0.2 & 0.2 & 0.2 \\
\hline Propyl paraben & 0.1 & 0.1 & 0.1 & 0.1 \\
\hline Water q. s to & 50 & 50 & 50 & 50 \\
\hline
\end{tabular}

*PEG: Poly Ethylene Glycol

\section{Characterization of HSLNs}

Prepared HSLNs were characterized and reported for potency measurement by UV spectrometer, surface morphology by SEM (JSM-6360LV Scanning Microscope; Tokyo, Japan), particle size and zeta potential by laser diffraction using zetasizer 3000 HSA (Malvern, UK) [19].

Evaluation of gels

Homogeneity

After the gels have been set in container, all gels were evaluated for homogeneity by visual inspection. They were evaluated for their appearance and presence of visible aggregates [27].

\section{Grittiness}

One millilitre of gel was taken on finger tips, and mildly rubbed between fingertips to check the grittiness [28].

\section{Measurement of $\mathrm{pH}$}

The $\mathrm{pH}$ of the gel was measured by using $\mathrm{pH}$ meter (Elico Li 613). One gram of gel was accurately weighed and dissolved in $100 \mathrm{ml}$ of distilled water. The solution was kept aside for two hours. The $\mathrm{pH}$ measurement was done in triplicate and average values are noted [28]

\section{Viscosity}

Viscosity of formulated gels was measured using Brookfield DVII+Pro viscometer (spindle number LV4) at the rotation speed of 50 $\mathrm{rpm}$ at room temperature. All the measurements were made in triplicate and average values were noted $[27,29]$.

\section{Extrudability}

The prepared gel formulations were filled into the collapsible aluminium tubes and crimped to the end. The filled tube weights were recorded. The gel filled tubes were placed between two glass slides and clamped. Five hundred grams of weight was placed over the slides and then the cap of the tube was removed. The amount of gel extruded was collected and weight of the extruded gel was noted.
The percentage of the extruded gel was calculated and concluded as below [30,31].

\section{$>90 \%$ Extrudability-Excellent \\ $>80 \%$ Extrudability-Good \\ $>70 \%$ Extrudability-Fair \\ Spreadability}

A sample of $0.5 \mathrm{~g}$ of each formulation was pressed between two slides uniformly to form a thin layer. Half kilogram of weight was permitted to rest on the upper glass plate for $5 \mathrm{~min}$. The diameter of the circle after spreading of the gel was determined. The results obtained are average of three determinations [32, 33]

\section{Study of wound healing activity in wistar albino rats}

\section{Experimental animals}

Male Wister albino rats weighing 150-225g were procured from Central Animal House, Uppal, Hyderabad, Telangana, India. Institutional Animal Ethical Committee approved the protocol for conducting animal study (No.316 1821/PO/Re/S/15/CPCSEA). The selected animals were housed 6 per each in acrylic cages at $22 \pm 2{ }^{\circ} \mathrm{C}$, $45-55 \%$ humidity and $12 / 12 \mathrm{~h}$ light/dark under controlled environment with free access to food and water, except during the study period. Rats were fed with standard laboratory diet and access to water was provided ad libitum. All efforts were made to minimise suffering and to reduce the number of animals used in the experiments. The rats were divided into six groups $(n=6)$. The animals were anesthetised using a mixture of etamine $\mathrm{HCl}(10$ $\mathrm{mg} / \mathrm{kg}$ ) and lidocaine $(40 \mathrm{mg} / \mathrm{kg}$ ) by i. p. injection. The animal fur in the dorsum was shaved with a sterilized electric razor. Excision wound model was followed for testing the wound healing activity $[34,35]$. A circular wound of about $1 \mathrm{~cm}$ was made under aseptic condition on depilated dorsal region of rats and was observed throughout the period of study. Rats were left undressed to the open environment. The formulations under study were applied daily until the complete healing. The group I acted as control, Group II was treated with standard marketed preparation (Povidone Iodine), 
group III, VI, V were served as test groups treated with solid lipid nanoparticles gel herbal formulations $[19,36]$. All rats were maintained individually in separate cages. Wound contraction and epithelialisation period was monitored. Wound contraction was measured as percent contraction and was calculated using the below formula. Percentage wound contraction $=\frac{\text { Initial wound Size }- \text { Specific day wound size }(\mathbf{n})}{\text { Initial wound size }} \times 100$

Where (n) = Number of days

\section{Statistical analysis}

The experimental results were expressed as the mean \pm SEM and oneway analysis of variance (ANOVA) followed by Dunnett's t-test was used to evaluate the statistical significance using the software graph pad Instant.

\section{RESULTS AND DISCUSSION}

We prepared two types of HSLNs, one with GMS and other with beeswax. The lipids were selected based on the solubility and miscibility of herbal extract of hibiscus in these lipids. As a general rule the entrapment efficiency of the active constituent would be higher if it is miscible/soluble with the lipid phase of the SLN [11]. In this research work, we could not quantify exact entrapment efficiency of this herbal extract in HSLNs because, unlike pure synthetic drugs, the herbal extract contains mixture of several phytoconstituents. However, like many herbal extracts, the overall wound healing activity in this case is due to the concoction of components present in the extract rather any single component.

Previously reported method was used for preparation of HSLNs [19, $37,38]$. Time required for homogenization to produce coarse emulsion and ultrasonication was optimised on several trials and errors. From the trials, 5 min of homogenisation and 3 min of ultrasonication was found to be optimal to produce required size range of solid lipid nanoparticles (below $500 \mathrm{~nm}$ ). The drug: lipid ratio was maintained constant across all experiments for the given lipid.

\section{Characterization of HSLNs}

In the HSLNs prepared using GMS and Beeswax, the potency of active constituents were found in the range of 90 to $110 \%$ of the expected theoretical potency. The surface morphology studies by SEM (fig. 1), revealed that the formulated HSLNs had near spherical shape. Mean particle size of selected GMS and beeswax formulations were found to be $\sim 534 \pm 32 \mathrm{~nm}$ and $\sim 176 \pm 22 \mathrm{~nm}$ (mean \pm SEM) with PDI of 0.248 and 0.396 respectively (fig. 2 (A and B). Low value of PDI is an indication that we could manufacture stable SLN with narrow size distribution range under optimal conditions. Zeta potential value of optimal formulation of GMS and beeswax was$10.4 \pm 2 \mathrm{mV}$ and $-11.0 \pm 2 \mathrm{mV}$ respectively.
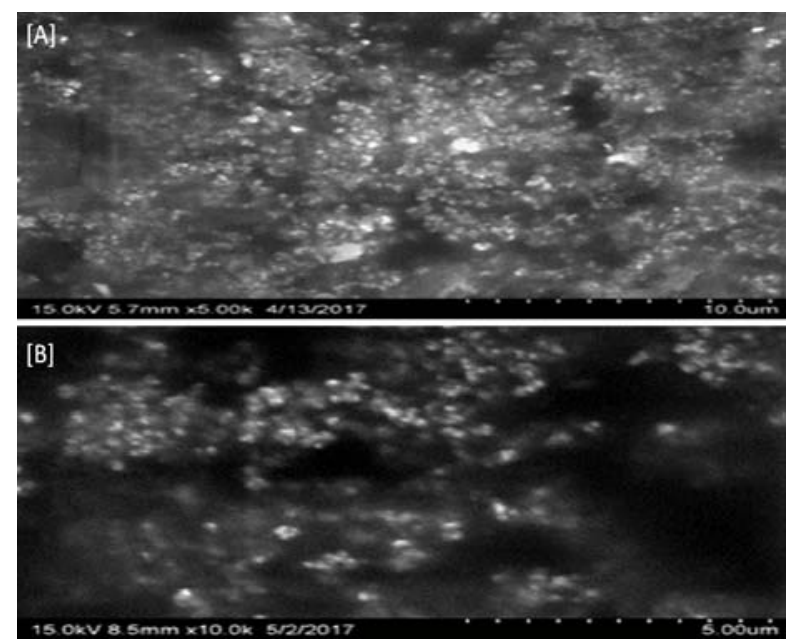

Fig. 1: SEM Images of GMS [A] and Beeswax [B] solid lipid nanoparticles

There was a significant difference $(p<0.05)$ between the particle sizes obtained for beeswax and GMS HSLNs (fig. 2 E). This difference of particle sizes may be due to the differences in chemical composition of these lipids.[39] When same level of emulsifiers used in both cases, the HSLNs prepared using beeswax demonstrated significantly lower particle size compared to GMS. This could be attributed to both viscosity of the lipids in the molten state and the surface charge on the particles. High negative or positive values of zeta potential, an indicator of surface charge, stabilizes SLNs and prevents aggregation (Malvern instruments., 2005).
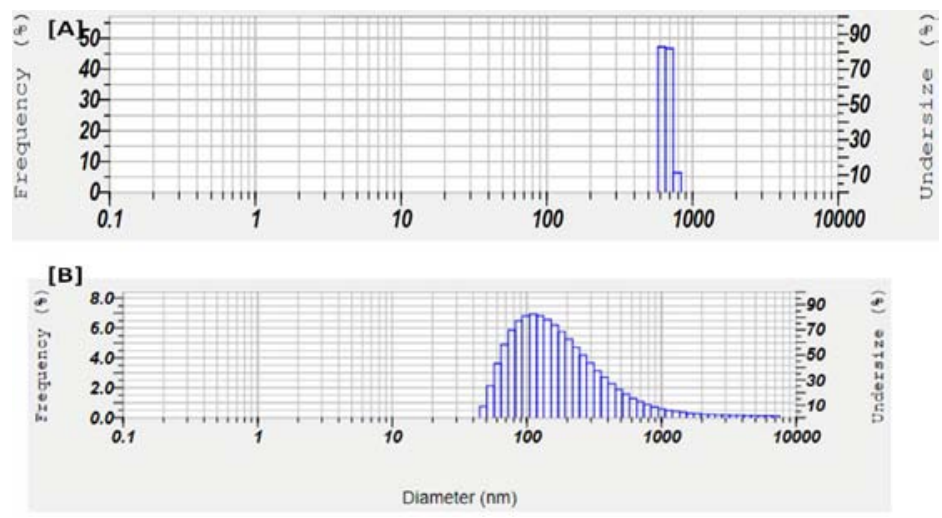

Fig. 2: Zeta-potential and mean particle size graphs of GMS [A] and Beeswax [B] HSLNs 
Beeswax is a mixture of various components compared to GMS Therefore, it can be expected that SLNs prepared using beeswax may demonstrate lower degree of crystallinity during storage as compared to SLNs prepared using GMS. As demonstrated by several authors [41, 42], high degree of lipid crystallinity may result in expulsion of the entrapped active constituent from the SLNs, in turn may affect the entrapment efficiency during prolonged storage. This expelled active constituent could affect the surface properties of the SLNs leading to particle aggregation. Therefore, to avoid such problems, HSLNs prepared with beeswax were considered best and taken for in vivo studies.

\section{Evaluation parameters of carbopol-940 gel}

Formulation containing $10 \mathrm{mg} / \mathrm{ml}$ of HSLNs has shown comparable wound healing activity as the marketed preparation. This formulation had required viscosity, spreadability and extrudability. Hence, this formulation is considered optimized and taken for stability studies for 3 mo.

Table 3: Evaluation parameters of carbopol-940 gel

\begin{tabular}{|c|c|c|c|c|c|c|c|c|}
\hline \multirow[t]{2}{*}{ Formulation code } & \multirow[t]{2}{*}{ pH } & \multirow{2}{*}{$\begin{array}{l}\text { Appearance and } \\
\text { homogeneity }\end{array}$} & \multirow[t]{2}{*}{ Grittiness } & \multirow{2}{*}{$\begin{array}{l}\text { Spreadability } \\
\text { (in } \mathrm{cm} \text { ) }\end{array}$} & \multirow{2}{*}{$\begin{array}{l}\text { Extrudability } \\
\text { (in \%) }\end{array}$} & \multicolumn{3}{|l|}{ Viscosity } \\
\hline & & & & & & (50rpm) & (60rpm) & (100rpm) \\
\hline F1 & $6.92 \pm 0.44$ & Translucent & Non-gritty & $6.32 \pm 1.46$ & $91 \pm 2.32$ & 1920 & 1632 & 1432 \\
\hline $\mathrm{F} 2$ & $6.53 \pm 0.34$ & Translucent & Non-gritty & $6.22 \pm 1.02$ & $88 \pm 3.44$ & 1950 & 1680 & 1490 \\
\hline F3 & $6.81 \pm 0.27$ & Translucent & Non-gritty & $6.24 \pm 1.43$ & $86 \pm 2.24$ & 2045 & 1702 & 1522 \\
\hline F4 & $6.88 \pm 0.43$ & Translucent & Non-gritty & $6.31 \pm 0.92$ & $90 \pm 2.52$ & 2053 & 1710 & 1561 \\
\hline
\end{tabular}

$n=3$

Table 4: Stability data of optimized gel formulation (F4)

\begin{tabular}{|c|c|c|c|c|c|c|c|c|}
\hline \multirow[t]{2}{*}{ Days } & \multirow[t]{2}{*}{ pH } & \multirow{2}{*}{$\begin{array}{l}\text { Appearance and } \\
\text { homogeneity }\end{array}$} & \multirow[t]{2}{*}{ Grittiness } & \multirow{2}{*}{$\begin{array}{l}\text { Spreadability } \\
\text { (in cm) }\end{array}$} & \multirow{2}{*}{$\begin{array}{l}\text { Extrudability } \\
\text { (In \%) }\end{array}$} & \multicolumn{3}{|l|}{ Viscosity } \\
\hline & & & & & & 50 (rpm) & $60(\mathrm{rpm})$ & 100 (rpm) \\
\hline 0 & $6.80 \pm 0.94$ & Translucent & Non-gritty & $5.10 \pm 0.55$ & $82 \pm 2.48$ & 3746 & 2780 & 2660 \\
\hline 1 & $6.83 \pm 0.72$ & Translucent & Non-gritty & $5.05 \pm 0.24$ & $80 \pm 2.44$ & 3746 & 2780 & 2660 \\
\hline 2 & $6.82 \pm 0.74$ & Translucent & Non-gritty & $5.30 \pm 0.72$ & $79 \pm 2.98$ & 3735 & 2775 & 2652 \\
\hline 3 & $6.80 \pm 0.62$ & Translucent & Non-gritty & $5.11 \pm 0.86$ & $79 \pm 2.56$ & 3722 & 2770 & 2635 \\
\hline
\end{tabular}

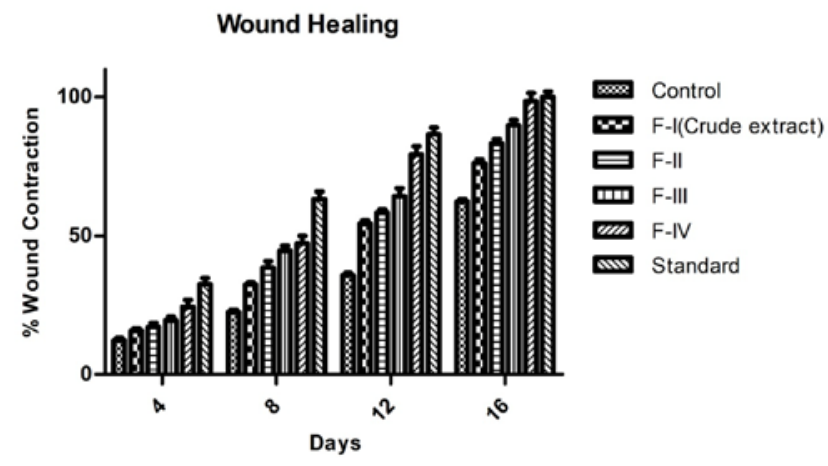

Fig. 3: Wound healing activity of HSLN gel formulations

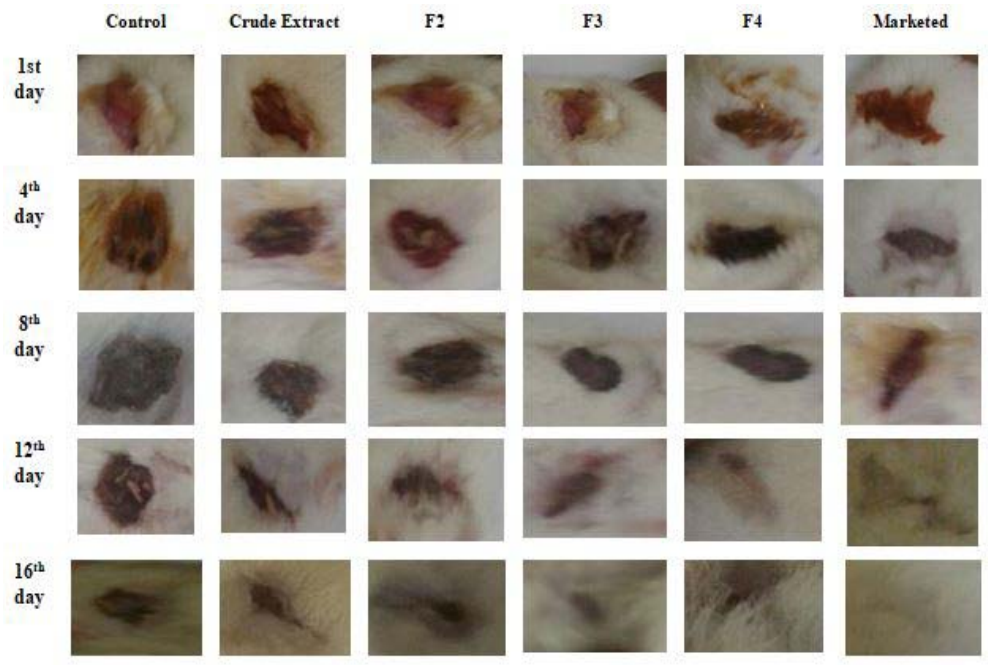

Fig. 4: Wound healing images of HSLN gel formulations on excision wound with control, crude extract (F1), F2-F4 and standard (marketed) 
All formulations prepared represented clear, homogenous, translucent gel networks free from lumps. The spreadability of all the gel formulations was good and extrudability was near $90 \%$ that is considered good to excellent. Viscosity of the formulations slightly increased with increase in HSLN concentration in the formulation. Carbopol 940 produces crosslinked network structure of gel and could be used as a suitable wound dressing material for topical applications [43]. Hydrogels prepared with Carbopol will provide depot release of drugs to the wound bed [44].

In this excision wound study the process of wound healing was noted at $4,8,12,16 \mathrm{~d}$ post operation. The contraction of wounds was faster in all the treated formulations compared to control showing superior wound healing efficacy of the hibiscus extract. This was in line with the reported literature $[20,21]$. Formulation containing $10 \mathrm{mg}$ per $\mathrm{ml}$ of HSLNs (F4) showed identical wound healing as that of the marketed preparation indicating increasing the HSLN concentration enhances the wound recovery. Also, the beeswax was reported to support the faster healing of the wounds [45] Both beeswax and hibiscus extract could have acted synergistically in faster healing process. Among these four formulation groups F3, F4 showed complete healing on 16th day while untreated groups (control) of animals took more than $30 \mathrm{~d}$ to complete for healing of wounds. There found no evidence of necrosis, haemorrhage and no indication of pain or inflammation on the animals. There was efficient keratinocyte migration and acceleration of reepitheliasation was observed. All the treated groups exhibited an efficient keratinocyte migration and acceleration in reepithelialisation process. Majority of the wounds healed in $12 \mathrm{~d}$ of initiation of the treatment. Though the faster healing was evidenced with higher concentration of HSLNs $(10 \mathrm{mg} / \mathrm{ml})$ but was not significantly better than the marketed preparation. However, this report is significant in showing the SLNs of the hibiscus extract was superior compared to hibiscus crude extract. Increasing the concentration of HSLNs in formulations may prove better and such possibilities can be tested in future studies.

In the present study, carbopol and PEG was used for the preparation of gel. The intrinsic tissue repair action of the SLNs in the gel-based system and its moisture controlling ability in the wound area was appearing to be strengthened. Carbopol is known to be a highly swellable polymer; in addition, the presence of PEG might have formed an interpolymeric complexation leading to an optimum and suitable moisture transmission properties for accelerated reepithelialisation. In contact with the wound exudates, the gel matrix might have swelled up to an ideal level creating an environment for efficient healing and reepithelialisation. In formulation F4, the high concentration of SLN could also have leached through the gel matrix favouring an optimum contact time between the surface of the wound and extract loaded SLN. This phenomenon might have facilitated the formation of microvasculature and skin tissue reconstruction in addition to reepithelialisation when compared to control.

\section{CONCLUSION}

In the current research work, we have prepared hibiscus extract loaded HSLNs by emulsion-quenching technique using two lipids GMS and Beeswax. HSLNs prepared using beeswax gave particle size of $\sim 175 \mathrm{~nm}$ and low distribution width (PDI 0.396). Beeswax HSLNs were incorporated into carbopol gel and tested for their wound healing activity in Wistar albino rats. The efficient keratinocyte migration along with acceleration in the process of reepithelialisation was observed in all the treated groups. All the treatment groups revealed an effectual keratinocyte exodus and progression in reepithelialisation. Within $12 \mathrm{~d}$ post-surgery, most of the wounds were observed to be completely healed. Wound healing rate of the gel containing $10 \mathrm{mg} / \mathrm{ml}$ of HSLNs (F4) was comparable to marketed formulation but was significantly faster compared to crude extract of Hibiscus rosa sinensis. In recent years, there is universal interest in the use of natural medicines and cost effective drug delivery systems to improve drug performance. This research work opens up new opportunities to explore SLNs as carriers for effective delivery of herbal drugs.

\section{FUNDING}

\section{AUTHORS CONTRIBUTIONS}

All the authors have contributed equally.

\section{CONFLICT OF INTERESTS}

Declare none

\section{REFERENCES}

1. NK Rajendran, SSD Kumar, NN Houreld, H Abrahamse. A review on nanoparticle based treatment for wound healing. J Drug Delivery Sci Technol 2018;44:421-30.

2. X Chen. Astragaloside IV-loaded nanoparticle-enriched hydrogel induces wound healing and anti-scar activity through topical delivery. Int J Pharm 2013;447:171-81.

3. S Bergin, P Wraight. Silver based wound dressings and topical agents for treating diabetic foot ulcers. Cochrane Database Syst Rev 2006; 25:CD005082.

4. BA Lipsky, C Hoey. Topical antimicrobial therapy for treating chronic wounds. Clin Infect Dis 2009;49:1541-9.

5. JM Dasam U, Natarajan J, Karri VVSR, Wadhwani AD, Antony J. Targeting efficacy of simvastatin for hormone-dependent carcinomas through solid lipid nanoparticles. J Nanomed Nanotechnol 2006;7:1-7.

6. X Yang, Y Liu, C Liu, N Zhang. Biodegradable solid lipid nanoparticle flocculates for pulmonary delivery of insulin. J Biomed Nanotechnol 2012;8:834-42.

7. W Mehnert. Solid lipid nanoparticles production, characterization and applications. Adv Drug Delivery Rev 2001;47:165-96.

8. P Ekambaram, AAH Sathali, K Priyanka. Solid lipid nanoparticles: a review. Int J App Pharm 2012;47:80-102.

9. S Küchler. 3D-wound healing model: influence of morphine and solid lipid nanoparticles. J Biotechnol 2010;148:24-30.

10. S Ghaffari. Nanotechnology in wound healing; semisolid dosage forms containing curcumin-ampicillin solid lipid nanoparticles, in vitro, ex-vivo and in vivo characteristics. Adv Pharm Bull 2018;8:395-400.

11. RV Punna Rao Ravi, N Aditya, Himanshu Kathuria, Srinivas Malekar. Lipid nanoparticles for oral delivery of raloxifene: Optimization, stability, in vivo evaluation and uptake mechanism. Eur J Pharm Biopharm 2014;87:114-24.

12. G Sandri. Wound dressings based on silver sulfadiazine solid lipid nanoparticles for tissue repairing. Eur J Pharm Biopharm 2013;84:84-90.

13. SH Khalid L, Rizwani GH, Sultana V, Zahid H, Khursheed R. Antidepressant activity of ethanolic extract of Hibiscus rosa sinenesis linn. Pak J Pharm Sci 2014;27:1327-31.

14. DX Hou, X Tong, N Terahara, D Luo, M Fujii. Delphinidin 3sambubioside, a hibiscus anthocyanin, induces apoptosis in human leukemia cells through reactive oxygen species-mediated mitochondrial pathway. Arch Biochem Biophys 2005;440:101-9.

15. A Herrera Arellano, S Flores Romero, MA Chavez Soto, J Tortoriello. Effectiveness and tolerability of a standardized extract from hibiscus sabdariffa in patients with mild to moderate hypertension: a controlled and randomized clinical trial. Phytomedicine 2004;11:375-82.

16. M Ali, A SH. Hair care and herbal drugs. Indian J Nat Prod 1997;13:3-5.

17. K PN, R VN, JP, Handbook of medicinal plants. New Delhi: Oxford and IBH Publishing Co. Pvt. Ltd; 1979.

18. IE Kate, OO Lucky. The effects of aqueous extracts of the leaves of hibiscus rosa-sinensis linn. on renal function in hypertensive rats. Afr J Biochem Res 2010;4:43-6.

19. P Vijayanand, V Jyothi, N Aditya, A Mounika. Development and characterization of solid lipid nanoparticles containing herbal extract: in vivo antidepressant activity. J Drug Delivery 2018 https://doi.org/10.1155/2018/2908626

20. B Shivananda Nayak, S Sivachandra Raju, FA Orette, AV Chalapathi Rao. Effects of Hibiscus rosa sinensis L (Malvaceae) on wound healing activity: a preclinical study in a sprague dawley rat. Int J Low Extrem Wounds 2007;6:76-81.

21. A Bhaskar, $\mathrm{V}$ Nithya. Evaluation of the wound-healing activity of hibiscus rosa sinensis L (Malvaceae) in wistar albino rats. Indian J Pharmacol 2012;44:694. 
22. PR Ravi, N Aditya, H Kathuria, S Malekar, R Vats. Lipid nanoparticles for oral delivery of raloxifene: optimization, stability, in vivo evaluation and uptake mechanism. Eur J Pharm Biopharm 2014;87:114-24.

23. B Gonul, D Erdogan, C Ozogul, M Koz, A Babul, N Celebi. Effect of EGF dosage forms on alkali burned corneal wound healing of mice. Burns 1995;21:7-10.

24. K Kiran, M Asad. Wound healing activity of sesamum indicum $L$ seed and oil in rats. Indian J Exp Biol 2008;46:777-82.

25. KP Mohammed Haneefa, A Abraham, R Saraswathi, GP Mohanta C Nayar. Formulation and evaluation of herbal gel of basella alba for wound healing activity. J Pharm Sci Res 2012;4:1642-8.

26. KA Shah, AA Date, MD Joshi, VB Patravale. Solid lipid nanoparticles $(\mathrm{SLN})$ of tretinoin: potential in topical delivery. Int J Pharm 2007;345:163-71.

27. P Vijayanand, J Patil, MV Reddy. Formulation, characterization and in vivo evaluation of novel edible dosage form containing nebivolol HCL. Brazilian J Pharm Sci 2016;52:179-89.

28. MC Gohel, RK Parikh, SA Nagori, SN Shah, MR Dabhi. Preparation and evaluation of soft gellan gum gel containing paracetamol. Indian J Pharm Sci 2009;71:120-4.

29. J Balasubramaniam, S Kant, JK Pandit. In vitro and in vivo evaluation of the gelrite gellan gum-based ocular delivery system for indomethacin. Acta Pharm 2003;53:251-61.

30. R Aiyalu, A Govindarjan, A Ramasamy. Formulation and evaluation of topical herbal gel for the treatment of arthritis in animal model. Brazilian J Pharm Sci 2016;52:493-507.

31. L Panigrahi, S Ghosal, S Pattnaik, L Maharana, B Barik. Effect of permeation enhancers on the release and permeation kinetics of Lincomycin hydrochloride gel formulations through mouse skin. Indian J Pharm Sci 2006;68:205-11.

32. MGB Dantas. Development and evaluation of stability of a gel formulation containing the monoterpene borneol. Sci World J 2016. Doi:10.1155/2016/7394685

33. D Vasudevan, R Rajan. Effect of permeation enhancers on the penetration mechanism of transfersomal gel of ketoconazole. J Adv Pharm Technol Res 2012;3:112.

34. PK Mukherjee, $\mathrm{R}$ Verpoorte, $\mathrm{B}$ Suresh. Evaluation of in vivo wound healing activity of hypericum patulum (Family:
Hypericaceae) leaf extract on different wound model in rats. Ethnopharmacol 2000;70:315-21.

35. R Pawar, P Chaurasiya, H Rajak, P Singour, F Toppo, A Jain. Wound healing activity of sida cordifolia linn. in rats. Indian J Pharmacol 2013;45:474.

36. D Mukherjee. Development and characterization of chitosanbased hydrogels as wound dressing materials. J Drug Delivery Sci Technol 2018;46:498-510.

37. S Mukherjee, S Ray, RS Thakur. Solid lipid nanoparticles: a modern formulation approach in drug delivery system. Indian J Pharm Sci 2009;71:349-58.

38. V Jenning, A Lippacher, SH Gohla. Medium scale production of solid lipid nanoparticles (SLN) by high pressure homogenization. J Microencapsul 2002;19:1-10.

39. CWWPDHR Hepburn. The chemistry of beeswax. In: Honeybee Nests, Springer, Berlin, Heidelberg; 2014. p. 319-39.

40. Pharmaceutical formulations and the importance of zeta potential to pharmaceutical formulations with supplier data. Malvern Instruments Ltd; 2005. Available from: https://www.azonano.com/article.aspx?ArticleID=1234. [Last accessed on 15 Dec 2019]

41. AF Kheradmandnia S, Vasheghani Farahani E, Nosrati M. Preparation and characterization of ketoprofen-loaded solid lipid nanoparticles made from beeswax and carnauba wax. Nanomedicine 2010;6:753-9.

42. MG Anthony, A Attama, Christel C. Effect of beeswax modification on the lipid matrix and solid lipid nanoparticle crystallinity. Colloids Surfaces A Physicochem Eng Asp 2008;315:189-95.

43. F Hayati, SM Ghamsari, MM Dehghan, A Oryan. Effects of carbomer 940 hydrogel on burn wounds: an in vitro and in vivo study. J Dermatolog Treat 2018;29:593-9.

44. BP Kermany. Carbopol hydrogels for topical administration: Treatement of Wounds; 2010.

45. M Abdulrhman, N Samir, El Barbary, D Ahmed Amin, R Saeid Ebrahim. Honey and a mixture of honey, beeswax, and olive oilpropolis extract in treatment of chemotherapy-induced oral mucositis: a randomized controlled pilot study. Pediatr Hematol Oncol 2012;29:285-92. 